\title{
Toward a common practice in the selection of earthquake ground motion criteria for the design of critical mining facilities at closure and post-closure
}

M Martinez Golder Associates S.A., Chile

A Hull Golder Associates Inc., USA

\begin{abstract}
The lack of a uniform engineering practice for earthquake design of critical mining facilities at the closure and post-closure stages can result in confusion for designers. Although local, international and company guidelines for critical mine facilities (e.g. tailings dam embankments, heap leach pads, rock waste dumps) are widely cited by designers, the selection of earthquake design levels for dynamic stability analyses are often arbitrary and can be inconsistent from site to site. Much of the inconsistency centres around how to use the earthquake ground motions developed from probabilistic seismic hazard analysis (PSHA) and deterministic seismic hazard analysis (DSHA).
\end{abstract}

At earlier stages of the mine planning, important elements in earthquake design of critical facilities at closure, post-closure and abandon are the site-specific earthquake hazard, the selection of the probabilistic and/or deterministic approach, and the seismic performance expectations.

The seismic hazard approach used in low hazard regions in stable continental regions differs significantly from that used for sites at high to very high seismic hazard regions like tectonic plate boundaries at subduction zones, or where seismogenic crustal faults have been mapped within about $100 \mathrm{~km}$ of the mine site. Adopting a combination of both PSHA and DSHA is generally recommended when seismic sources can be identified and characterised with confidence. At sites located in stable continental regions, PSHA is the best method to develop earthquake ground motions.

Modern international guidelines for seismic design of critical facilities typically recommended earthquake performance for an operating basis earthquake (OBE), and the safety evaluation earthquake (SEE). The SEE performance level defines the maximum earthquake ground motion to be resisted by the critical facility with acceptable damage but without a fatal collapse, or an uncontrolled release of materials in the case of dams. The SEE is usually proposed for closure, post-closure and abandonment.

The SEE performance level is typically based on the facility failure consequence and selected as the lesser of either the deterministic maximum credible earthquake (MCE), or the probabilistic spectral accelerations at low annual exceedance probabilities (AEP) of up to 1 in 10,000 (or 1:10,000). The median or $84^{\text {th }}$-percentile maximum credible earthquake ground motions have no return periods associated.

This paper suggests criteria for a consistent engineering guideline for the seismic analysis and design of critical mine facilities. It describes how current probabilistic and deterministic approaches complement earthquake performance assessment of critical mining facilities located in different seismic hazard regions.

Keywords: earthquake, seismic hazard, performance, probabilistic, deterministic, failure consequence

\section{Introduction}

Closure, post-closure and eventual abandonment of critical mining facilities (e.g. tailings storage facilities, water storage dams, lined ponds, rock waste dumps, and heap leach pads) involve engineering evaluations from the early stages of the mine development plan to address long-term physical, chemical, ecological and 
social stability: confirming the earthquake ground motion criteria is a critical decision for the owner and engineering design team. Earthquake ground motions are needed for both new and existing facilities irrespective of whether it is located in a region of low, moderate or high seismic hazard.

The unique features of critical mine facilities exclude the application of local seismic provisions for standard structures for human occupancy. Earthquake ground motions developed for local seismic building codes are not applicable for the design and analysis of critical mining facilities because they are neither site-specific, nor for useful beyond life-safety design for standard structures. As a consequence, earthquake analysis and design of critical mining facilities for closure needs to be based on a specific approach that combines the sitespecific seismic hazard with an expected earthquake performance target defined by its failure consequence.

Although international guidelines for critical facilities are widely cited by designers, the selection of design earthquake ground motions can often be confusing. For instance, the guidelines for seismic analysis and design of water reservoir dams and tailings storage facilities (TSF) are widely used (e.g. International Commission on Large Dams (ICOLD) 2010, 2016; Canadian Dam Association (CDA) 2014; New Zealand Society on Large Dams (NZSOLD) 2016; Australian National Committee on Large Dams (ANCOLD) 2017, Garbarino et al. 2018, etc.). However, the appropriate selection of earthquake ground motion outputs for a selected performance level still remains unclear, often leading to the adoption of arbitrary level for seismic design.

This paper intends to clarify the use of current international guidelines and proposes an approach toward developing a common practice to the selection of earthquake ground motions for seismic stability analysis and design of critical facilities. Consistent with most guidelines, the approach uses both probabilistic (PSHA) and deterministic seismic hazard analyses (DSHA), including ways to reconcile the different results that come from the two analysis methods.

The earthquake hazard curves presented here are mean horizontal accelerations generalised from the results of site-specific seismic hazard studies undertaken by Golder Associates in low, moderate and high seismic hazard regions worldwide. Earthquake ground motion values presented are generalised and not suitable for use in design. A glossary is included at the end of this paper to assist in the definition of technical terms.

\section{$2 \quad$ Site-specific seismic hazard}

Seismic hazard arises from earthquake occurrence that is typically a geographically defined and related to a geologic province and the present-day tectonic framework. Location with respect to tectonic plate boundaries, seismically active crustal faults, and the historical existence of earthquakes are key elements in the assessment of seismic hazard at a site.

Table 1 lists the key parameters that describe the main features that can be used to classify a site into three general regions of seismic hazard. These features account for the geological and seismic setting, the average slip rate on mapped faults, and the maximum expected earthquake magnitude. Table 1 also indicates the ease of defining the maximum credible earthquake (MCE) for conducting DSHA based on applicable data available in the region surrounding a site.

\section{Earthquake hazard and return periods}

The currently available international guidelines for earthquake ground motion selection for mine facility design are typically based on discrete annual exceedance probabilities (AEP, or their inverse of return period), and for a specified failure consequence. Understanding the interrelation between PSHA- and DSHA-based earthquake ground motions and their AEP is critical to the selection of earthquake design ground motions. Furthermore, the use of PSHA and/or DSHA to evaluate earthquake ground motions for design depends on the regional seismic hazard level where the critical facility is located. The influence of seismic region on the selection of ground motions is described further herein and summarised in Table 1. 


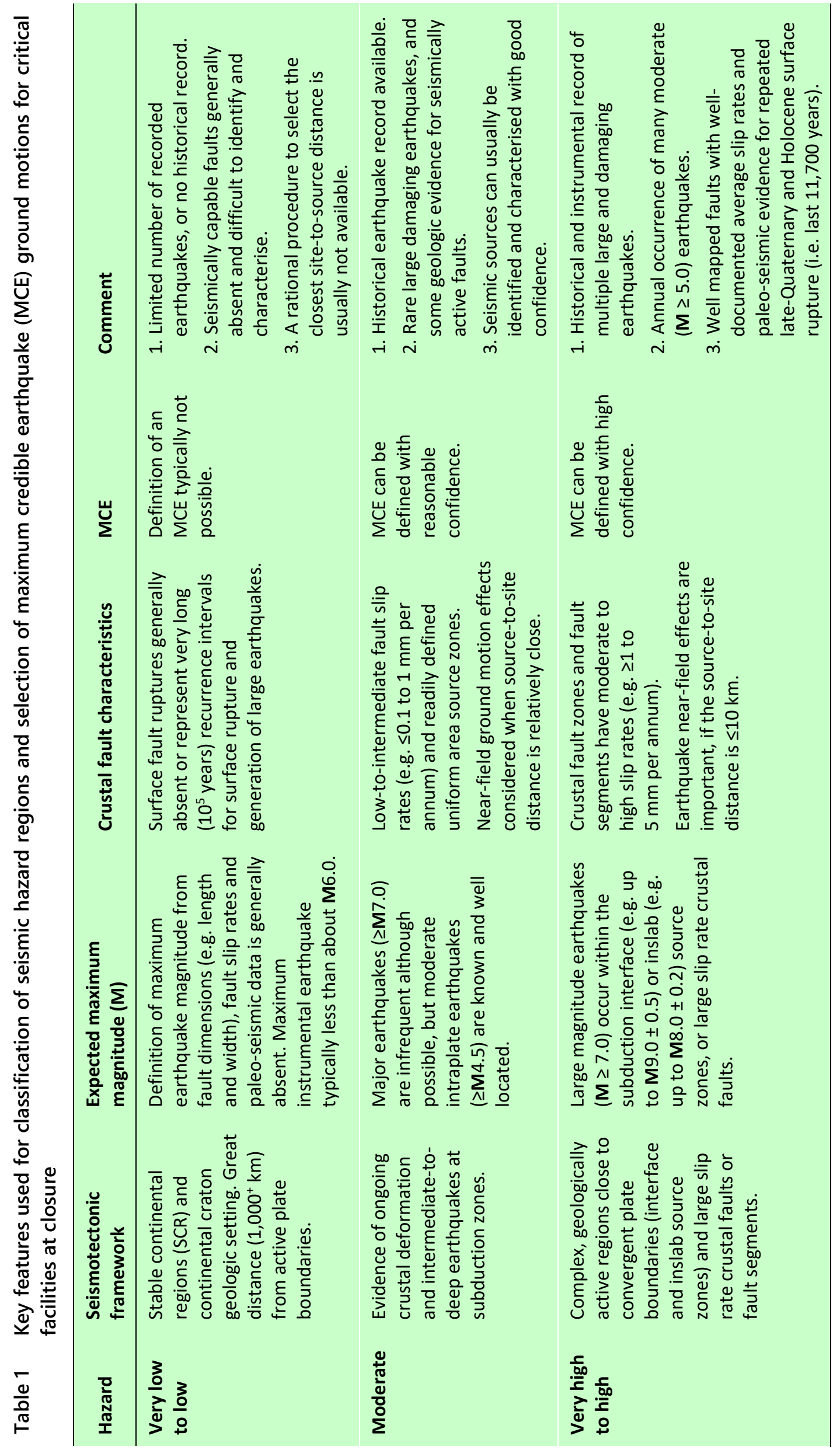




\subsection{Very low and low seismic hazard regions}

Regions of very low to low historical earthquake activity are typically within the cratons of the major continents. Cratons are generally geologically old (i.e. billions of years) and tectonically stable parts of the continental lithosphere that have persisted through a number of cycles of continental accretion and rifting. Cratons typically consist of crystalline basement rocks that are sometimes covered and/or flanked by younger sedimentary rock units. Johnston et al. (1994), considers a stable continental regions (SCRs) to be an area that has not experienced any major tectonism or orogenic activity (i.e. major crustal deformation) younger than early Cretaceous (i.e. 140 million years [Ma] ago), and no rifting or major extension or trans-tension since Paleogene time (i.e. 66 to $56 \mathrm{Ma}$ ago). The relatively historical seismic quiescent in SCRs often makes it difficult to develop a robust estimation of the earthquake recurrence parameters needed for probabilistic analyses. Because the maximum horizontal compressive-stress directions are relatively uniform within the SCRs (Johnson 1994), the estimation of acceptable earthquake activity parameters is generally based on uniform area crustal earthquake source zones that assume a uniform frequency of earthquake occurrence across the whole area (Cornell 1968).

The SCRs typically do not contain seismically active faults associated with large earthquakes in historical or Holocene times. Some exceptions to this general rule are, however, known from regions of the world including Australia and the Fennoscandia region of northern Europe (Landgraf et al. 2017). In Australia, analysis of the tectonic geomorphology shows the potential for large surface fault rupturing earthquakes with at least historical time on faults in Western Australia and near the centre of the SCR (e.g. Quigley et al. 2010). Quigley et al. (2006) mapped a number of Quaternary faults in the western Flinders Ranges of South Australia to estimate their average fault slip rates of 0.05 to $0.06 \mathrm{~mm}$ per annum and recurrence intervals of 30,000 to 60,000 years for surface rupturing earthquakes. The very long recurrence intervals and low average slip rates for these faults suggested that they will have limited impact for sites where a maximum return period of 10,000 years is considered.

In Fennoscandia of northern Europe, changes in crustal stresses from glacial isostatic adjustment have been used to explain postglacial surface fault rupture (e.g. Wu et al., 1999; Sutinen et al. 2015). Postglacial faults have been mapped in Finland, Sweden, and Norway (e.g. Grigull et al. 2015; Olesen et al. 2004; Sutinen et al. 2015). The onset of surface fault activity in Fennoscandia started at end of the Weichselian deglaciation phase, with maximum fault instability estimated to have occurred at about 13,000 to 10,000 years ago (Korja 2015). Faults in Fennoscandia have been mapped for lengths up to $70 \mathrm{~km}$ and with scarps up to $30 \mathrm{~m}$ high. Because fault activity appears linked to recent, rapid deglaciation and most fault ruptures occurred more than 10,000 years ago, it is unclear whether these faults are capable of future surface rupture under the present-day stress condition.

In low seismic hazard regions, the identification and characterisation of fault sources is typically very difficult because even when active faults are present, they are difficult to identify. Accordingly, finding the source of the MCE needed to undertake a DSHA is not practical. The results from PSHA, therefore, are usually used to develop design earthquake ground motions for mine sites.

In very low to low seismic hazard regions, design-level earthquake ground motions are typically selected for low AEPs (e.g. 1:2,500 to 1:10,000) depending on the facility failure consequence rating. However, earthquake ground motion values are typically low and may not control the design, even when the earthquake ground motions are selected for a low or very low AEP (e.g. peak ground acceleration (PGA) $\approx$ $0.20 \mathrm{~g}$ for an AEP of 1:10,000).

Figure 1 shows a typical probabilistic earthquake hazard curve for mean horizontal PGA (expressed as a fraction of the acceleration of gravity, $\left.g\left(9.805 \mathrm{~m} / \mathrm{s}^{2}\right)\right)$ in a generic low seismic hazard region. 


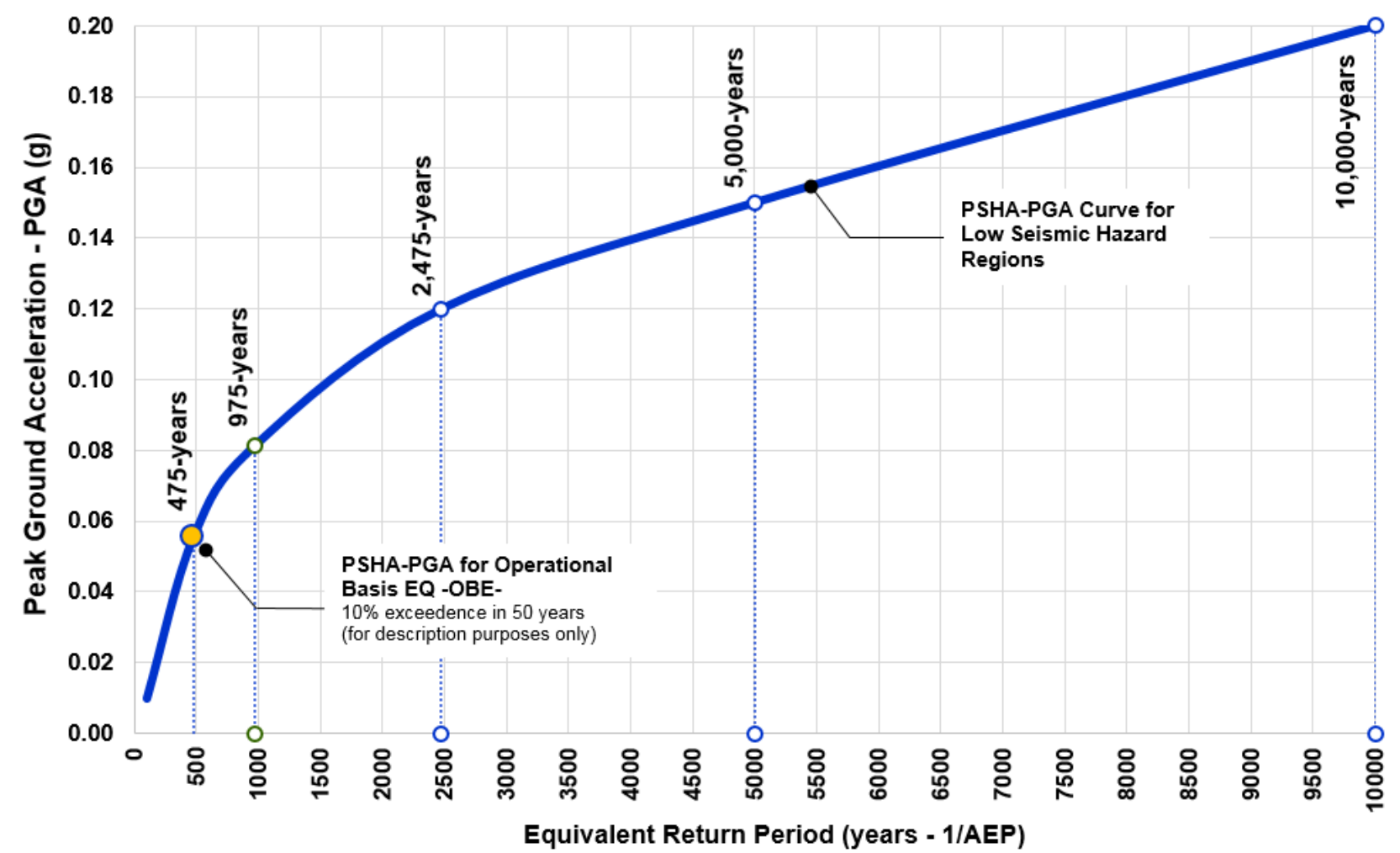

Figure 1 Characteristic peak ground acceleration (PGA) hazard curve in a very low to low seismic hazard region (Disclaimer: ground motion values are referential and for description purposes only)

\subsection{Moderate seismic hazard regions}

Figure 2 shows a mean horizontal PGA hazard curve typical for a region with a moderate level of seismic hazard. Moderate seismic hazard regions are typically located away from present-day tectonic plate boundaries but not within the adjacent SCRs. At subduction zones, moderate seismic hazard regions are where subduction inslab earthquakes occur at depths $\geq 100 \mathrm{~km}$ below the surface as the subducting plates are extended and sink into the mantle. Crustal deformation is typically associated with faults away from the plate boundary with seismically active fault systems with lower ( $\leq 1 \mathrm{~mm}$ per annum) average slip rates and distributed earthquakes throughout the region with intermediate rates of occurrence.

In moderate seismic hazard regions, earthquake recurrence parameters can be estimated based on historical and instrumental record of earthquakes. Evidence for the location and activity of any seismogenic faults is variable, so fault activity parameters often require estimation with wide ranges in uncertainty. Uniform or gridded-area crustal earthquake source zones based on earthquake catalogues are used to characterise regions with no obvious surface faults.

As indicated in Table 1 there are usually sufficient data available to define the source of the MCE, and to estimate the median, or the $84^{\text {th }}$-percentile (median plus one standard deviation) ground motions originating from the MCE source. In moderate seismic-hazard regions, the MCE median ground motion values are generally closer to or greater than the 1:475 AEP, and the MCE $84^{\text {th }}$-percentile ground motions typically associated with an AEP of about 1:2,500 to 1:5,000 (Figure 2).

\subsection{High and very high seismic hazard regions}

Figure 3 shows the probabilistic mean PGA hazard curve for a typical high to very high seismic hazard region. These seismic hazard regions are located within or close to major present-day tectonic plate boundaries such as the margins of much of the Pacific Ocean or the 'Ring of Fire,' the Mediterranean, and India-Asian. 


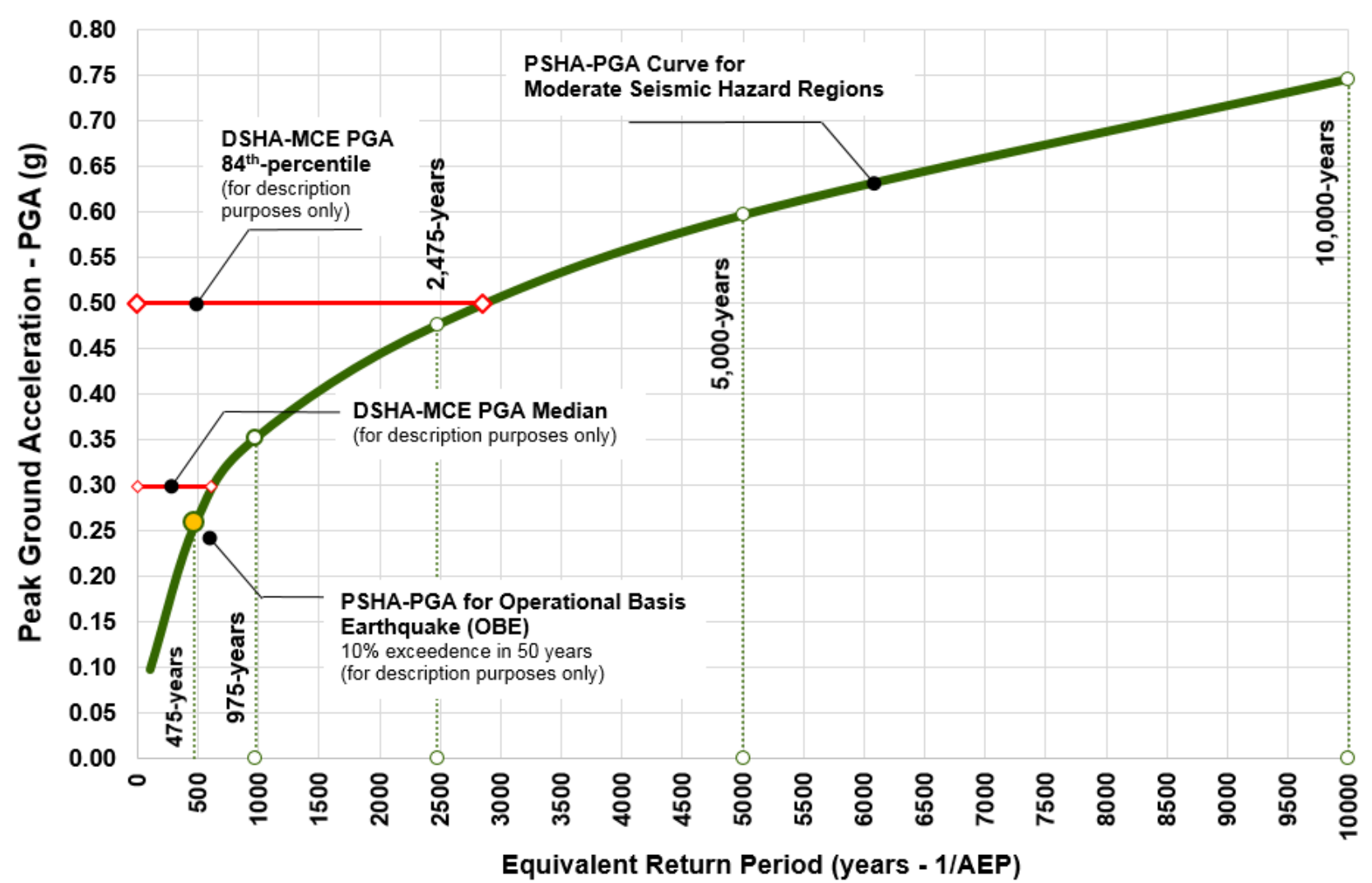

Figure 2 Characteristic seismic mean horizontal peak ground acceleration (PGA)-curve for moderateearthquake hazard regions (disclaimer: ground motion values are referential and for description purposes only)

In high to very high seismic hazard regions, earthquakes occur because of the ongoing active tectonics associated with plate boundaries, such as plate convergence at subduction zones and high slip rate seismogenic faults at transform boundaries. The major faults in these regions typically have evidence for repeated surface ruptures.

In high seismic hazard regions, a robust analysis of earthquake recurrence parameters can usually be undertaken from the historical (i.e. pre-instrumental) and instrumental record of earthquakes; and good evidence of past surface fault rupture. Uniform or gridded-area crustal earthquake source zones based on earthquake catalogues can be included to characterise regions with no obvious surface faults.

Figure 3 shows that spectral accelerations (e.g. PGA) are generally much greater than those in low and moderate seismic hazard regions. The $84^{\text {th }}$-percentile MCE PGA acceleration is typically associated with AEPs from about 1:500 to 1:2,500 in very high and high seismic hazard regions.

In high seismic hazard regions, the median MCE accelerations are typically closer to or even below the 1:475 AEP. This is particularly evident in regions with (very) frequent large events where paleo-seismic studies indicate greater subduction earthquakes and surface fault ruptures with short recurrence intervals (e.g. Chile-Peru, Alaska, San Andreas and Sumatran faults).

\section{Proposed selection criteria: probabilistic versus deterministic earthquake ground motion severity}

Figure 4 shows the relationship between mean horizontal PGA hazard curves developed from PSHA and the $84^{\text {th }}$-percentile MCE PGA values from the three seismic hazard regions above. By definition, the MCE scenario represents the largest reasonably conceivable earthquake considered possible along a recognised fault, or within a tectonic province' (ICOLD 2010, 2016). 


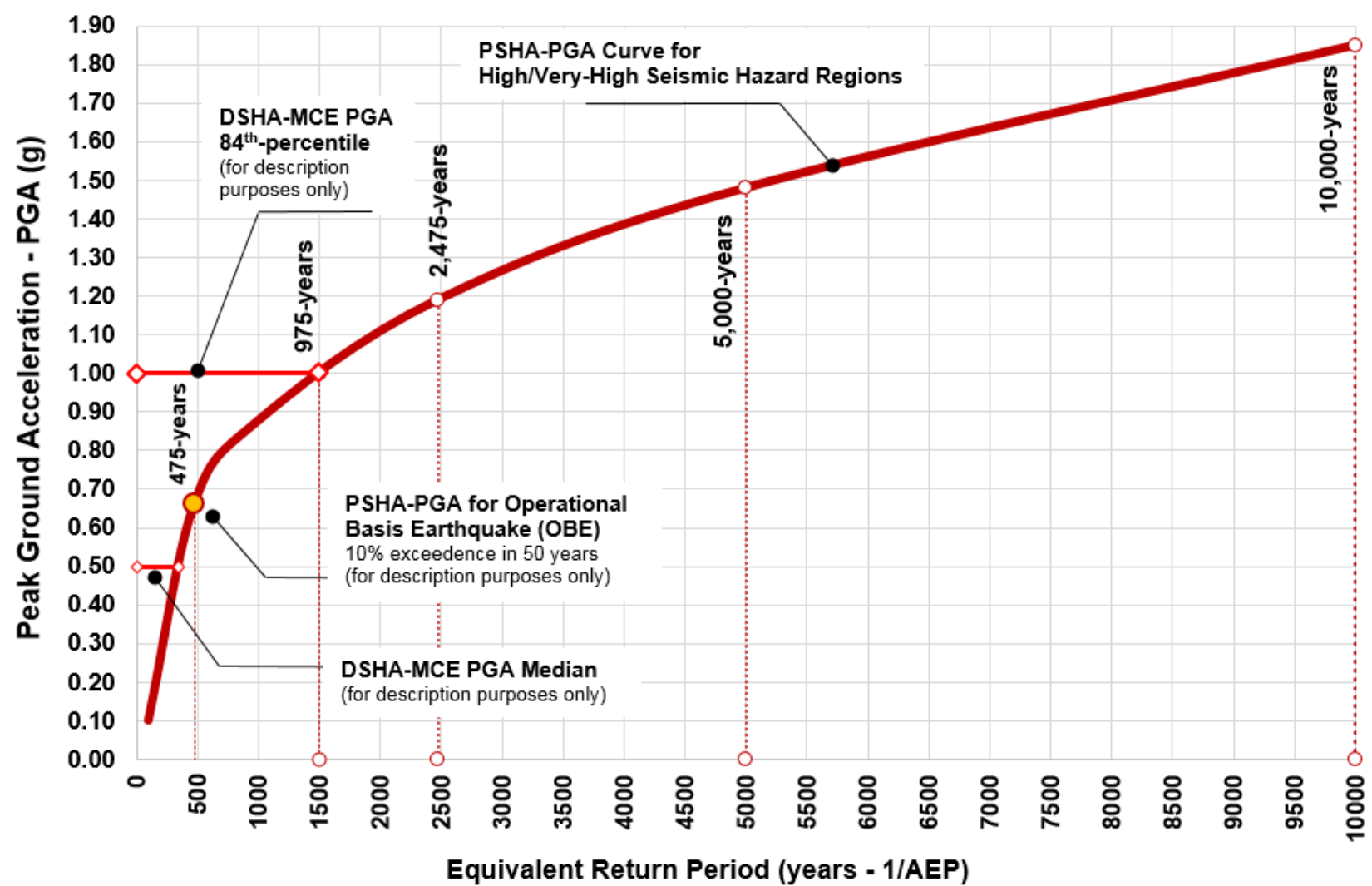

Figure 3 Characteristic seismic hazard peak ground acceleration (PGA)-curve for very high to high earthquake hazard regions (Disclaimer: ground motion values are referential and for description purposes only)

If the earthquake ground accelerations estimated for the MCE are lower than those calculated from the PSHA approach (e.g. for an AEP of 1:10,000), then the 'largest reasonably conceivable' MCE accelerations will likely control the seismic design of the critical facility. Otherwise, the probabilistically based earthquake ground motions for the appropriate AEP can be applied. The earthquake ground motion severity adopted will be the MCE ground motion (median or $84^{\text {th }}$-percentile), or the ground motion for the selected AEP for the facility failure consequence, whichever is lower.

Design earthquake ground motions in very low and low hazard regions where the MCE cannot be defined (Table 1, Figures 1 and 4) can be for low to very low AEPs (e.g. AEP of 1:2,500 to 1:10,000) depending on the failure consequence rating.

In moderate seismic hazard regions, the MCE $84^{\text {th }}$-percentile accelerations typically have AEPs of $1: 2,500$ to 1:5,000, with relatively high values. Earthquake ground motion values for lower AEPs (e.g. 1:5,000 to 1:10,000) appear feasibly for dam design at moderate seismic hazard regions as shown in Figures 2 and 4.

For high and very high seismic hazard regions, large earthquakes are typically very frequent, and the return periods for higher value earthquake ground motions are shorter than in low to moderate hazard regions. These strong earthquakes typically produce very high accelerations at the site (Figures 3 and 4).

In high seismic regions, the $84^{\text {th }}$-percentile MCE accelerations are typically bounded by accelerations with AEPs of about 1:500 to 1:2,500, and accelerations for AEPs lower than about 1:2,500 appear unnecessary for critical facilities' seismic design. As expected, MCE median ( $50^{\text {th }}$-percentile) accelerations generally have short equivalent return periods (Figures 2 and 3 ). 


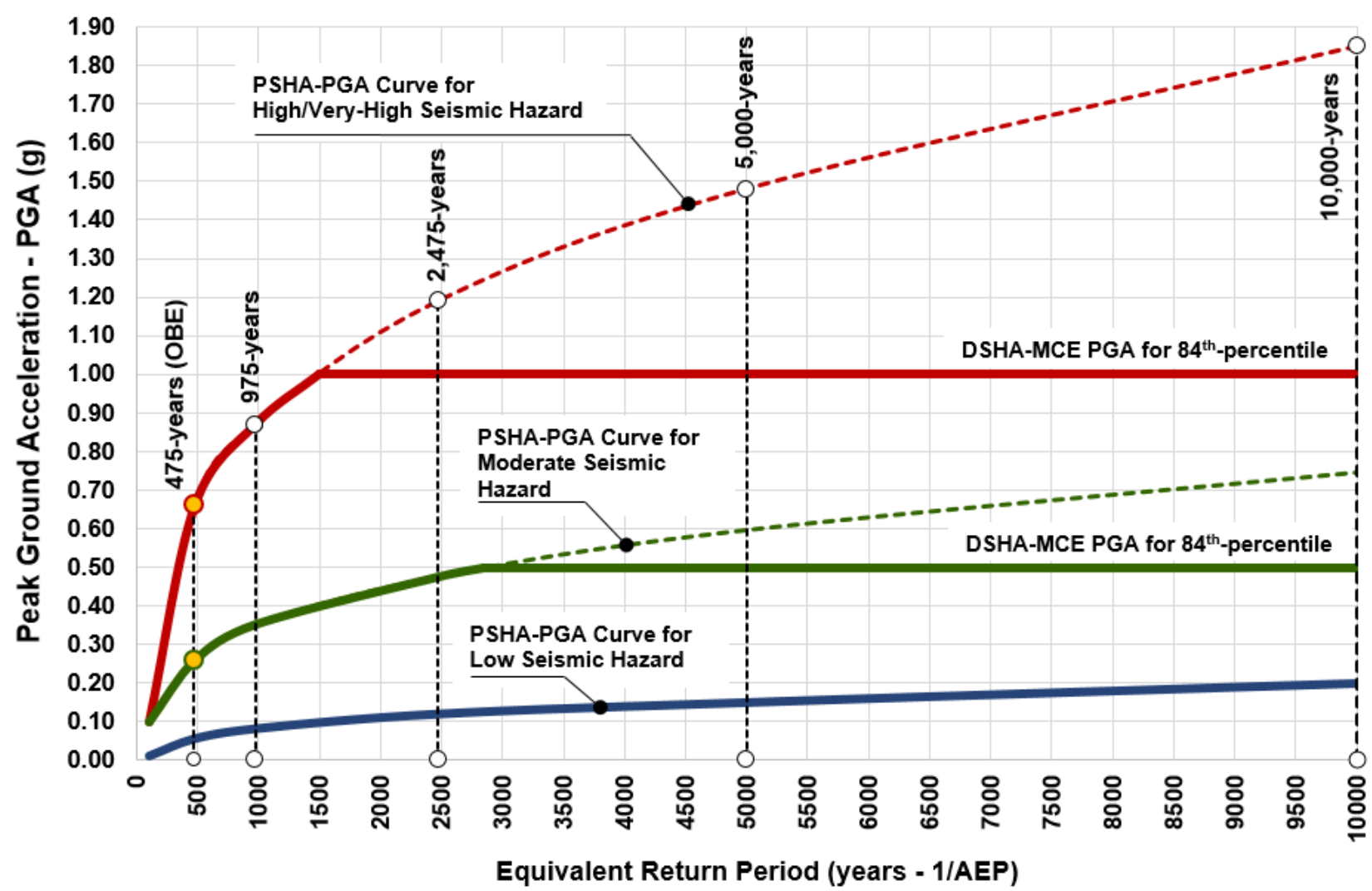

Figure 4 Typical peak ground acceleration (PGA) hazard curves for low, moderate and high earthquake hazard regions (Disclaimer: ground motion values are referential and for description purposes only)

Figure 4 shows that the adoption of low to very low AEPs (i.e. long earthquake recurrence intervals) to provide additional conservatism for the seismic design of critical facilities is unnecessary, particularly in moderate to high seismic hazard regions. The earthquake ground motions adopted for stability analysis and seismic design of critical facilities in moderate to high seismic hazard regions should be evaluated using both probabilistic and deterministic approaches with comparison of MCE ground motions (median and $84^{\text {th }}$ perentile) to ground motions with a range of AEPs.

\subsection{Period range of interest for dynamic deformation analyses}

Unlike the pseudo-static stability analysis that uses only PGA accelerations, earthquake ground motions used in dynamic stability analyses are generally developed for a period range of interest. For typical TSF embankment dams for modern mines, the period range of interests is typically in the range of about $0.2 \mathrm{~s}$ to $1.0 \mathrm{~s}$ (i.e. near the natural period of the dam structure).

Figure 5 illustrates the probabilistic mean hazard curves and the $84^{\text {th }}$-percentile MCE accelerations for three spectral periods (i.e. PGA, $0.2 \mathrm{~s}$ and $1.0 \mathrm{~s}$ ) and for the three seismic hazard regions. These hazard curves can be used to evaluate the impact on earthquake acceleration return period for spectral periods other than PGA.

For $84^{\text {th }}$-percentile MCE accelerations, Figure 5 shows that similar AEPs (i.e. the reciprocal of return period) for PGA and $0.2 \mathrm{~s}$ and for both moderate and high seismic hazard regions have AEPs ranging from about 1:500 to $1: 2,500$ in high seismic regions, and $1: 2,500$ to $1: 5,000$ in moderate seismic hazard areas. For the $1.0 \mathrm{~s}$ spectral period, the $84^{\text {th }}$-percentile MCE accelerations typically have lower AEPs (i.e. longer earthquake return periods). 

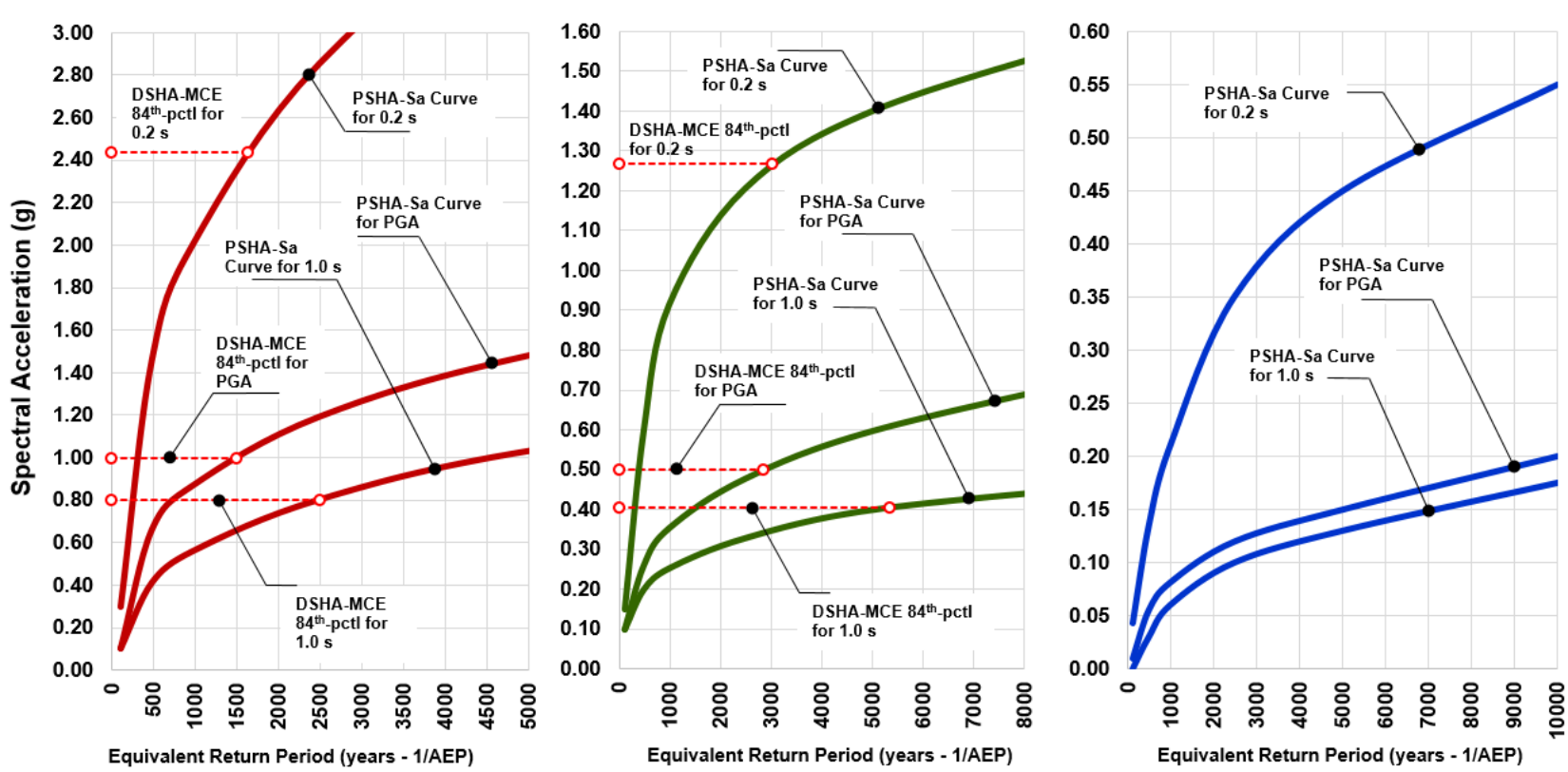

Figure 5 Typical mean hazard curves and $84^{\text {th }}$-percentile maximum credible earthquake (MCE) spectral accelerations for peak ground acceleration (PGA), $0.2 \mathrm{~s}$ and $1.0 \mathrm{~s}$ for high (left), moderate (centre) and low (right) seismic hazard regions (Disclaimer: ground motion values are referential and for description purposes only)

\subsection{Uncertainties and the impact on earthquake ground motion return periods}

Based on the current international standard of practice, probabilistic earthquake ground motions are provided as mean values (e.g. curves in Figure 4) estimated from a number of weighted ground motion models (GMMs) selected for their relevance to seismic sources included in a seismic model. Rather than using the mean seismic hazard curve, hazard modellers are now recommending that designers consider a band of ground motions (e.g. between the $5^{\text {th }}$ - and $95^{\text {th }}$-fractile around the mean values) to capture the uncertainties associated with the probabilistic analysis.

The correlation between the mean curve of ground motions and their equivalent return periods, as shown in Figure 4 , can be complemented by review of the upper- $\left(95^{\text {th }}\right.$-fractile) and lower-bound ( $5^{\text {th }}$-fractile) hazard curves developed for the identification, quantification and incorporation of uncertainties within the probabilistic analysis.

The lower-bound hazard curves (i.e. $5^{\text {th }}$-fractile) will show longer return periods, while upper-bound hazard curves (i.e. $95^{\text {th }}$-fractile) have shorter return periods. As a corollary, the aleatory variability and the epistemic uncertainty affect the mean ground motion values and their return period and should be reviewed for seismic stability analysis and seismic design of critical facilities for mine closure.

\section{$5 \quad$ Earthquake ground motions for critical facilities at closure}

Current international guidelines emphasise the importance of safe, sustainable, and environmentally responsible operation management of critical mining facilities using a risk-based approach throughout the entire lifecycle, including closure and post-closure. There is at present a wide variation in acceptable design life periods for the long-term stabilisation of physical conditions in critical mining facilities suggested in international guidelines. There is an increasing expectation worldwide that critical facilities (e.g. TSF embankment dams) must be capable of showing physically stable conditions in 'perpetuity', or for a period in excess of 1,000 years (e.g. International Council on Mining and Metals (ICMM) 2008; ICOLD 2013; Schafer et al. 2018). 
At the same time, the MCE ground motions are commonly used for the design earthquake ground motion to ensure the physical stability of critical closure construction, post-closure, and ultimate facility abandonment. However, as shown in this paper, the MCE ground motions may not be applicable in low seismic hazard regions and may have different return periods, depending on the seismic hazard region where the facility is located (Figure 4). Also, international guidelines do not identify whether the median or $84^{\text {th }}$-percentile MCE ground motion should be used for closure design.

The earthquake ground motion selection criteria recommended for long-term closure of critical mining facilities should be based on both the understanding of the specific seismic hazard at the site where the facility is located, and the expected seismic performance target as indicated in international local or industry guidelines and standards.

A significant number of earthquake performance targets are specified in different guidelines and industry standards. However, the operating basis earthquake (OBE) and the safety evaluation earthquake (SEE) are two common earthquake performance levels used in critical mining facilities.

The OBE represents the earthquake ground motion level for which the facility is designed to remain operational, with any damage being minor and readily repairable following the earthquake occurrence. OBE ground motions can reasonably be expected to occur during the operating life of the dam. While the OBE performance level typically has an AEP of 1:475 or even shorter return periods, the SEE ground motion is typically selected as the performance level for closure, post-closure and abandonment based on the failure consequence of critical mining facilities.

\subsection{Earthquake ground motions for the SEE performance level}

\subsubsection{Failure consequence}

Existing international guidelines for the design of critical facilities recommend that the failure consequence be based on a qualitative and quantitative analysis of the consequence of a hypothetical collapse. Guidelines typically define a minimum of three main failure targets; low, high and extreme, with the ranking dependent on the human, environmental and economic consequences of the structure collapse (e.g. number of lives lost, long-term environmental consequences etc.).

\subsubsection{SEE ground motion performance level}

The SEE is the most severe earthquake ground motion that a critical facility must be able to endure, and for which the structure should be designed or analysed (e.g. ICOLD 2010, 2016). The SEE term replaces the design basis earthquake (DBE) and the maximum design earthquake (MDE) terms used in the earlier editions of ICOLD.

Under the SEE, facilities can be damaged but must retain functionality. Damage may be extensive, operation may be disrupted, or economic losses may be significant (Wieland 2012, 2016). However, the facilities' structural integrity needs to be maintained and, for instance, in the case of dam embankments, uncontrolled release of water and or tailings must be prevented. The SEE is the performance target that should guarantee long-term sustainable physical stability of critical mining facilities designed and validated for closure, post-closure and abandonment. Table 2 lists common SEE earthquake ground motion selection criteria for seismic stability design of critical facilities at closure, post-closure and abandonment stages.

During the SEE, plastic deformations may occur in different sections of the facility. As result, time domain dynamic deformation stability analyses must be undertaken through the use of synthetic scaled or spectrally matched acceleration time histories (ATH). 
Table 2 Ground motion selection criteria for critical facilities at the mine closure stage

\begin{tabular}{lll}
\hline $\begin{array}{l}\text { Failure } \\
\text { consequence }\end{array}$ & Ground motion selection criteria & $\begin{array}{l}\text { Earthquake ground motion annual } \\
\text { exceedance probability (AEP) }\end{array}$ \\
\hline Extreme & $\begin{array}{l}\text { The lesser of maximum credible } \\
\text { earthquake (MCE) } 84^{\text {th }} \text { percentile and AEP }\end{array}$ & $\begin{array}{l}1: 10,000(\approx 0.5 \% \text { probability of } \\
\text { exceedance in } 50 \text { years })\end{array}$ \\
High & The lesser of MCE $84^{\text {th }}$ percentile and AEP & $\begin{array}{l}1: 5,000(\approx 1 \% \text { probability of } \\
\text { exceedance in } 50 \text { years })\end{array}$ \\
Low & The lesser of MCE $50^{\text {th }}$ percentile and AEP & $\begin{array}{l}1: 2,500(~ \\
\text { exceedance in } 50 \text { years })\end{array}$ \\
\end{tabular}

Note: The conventionally accepted MCE definition is used in this paper (see Glossary).

\section{Conclusion}

Current international guidelines provide earthquake ground motion selection criteria for the analysis and design of critical facilities in mining. While these guidelines show clear definitions of the expected earthquake performance levels, it often remains unclear which specific ground motions should be used, particularly for the SEE that is usually adopted for mine closure. This lack of clarity often leads to confusion, inconsistencies, and the arbitrary selection of earthquake ground motions for analysis. In many cases, the confusion arises because there is not always a good understanding of the nature and application of the probabilistic and deterministic approaches to the development of earthquake ground motions for seismic design.

For the SEE performance level, the facility failure consequence should be assessed because it influences the ground motions recommended for design and closure. We suggest that the lower of the $84^{\text {th }}$-percentile MCE, or the 1:10,000 AEP and 1:5,000 AEP earthquake ground motions be used for analysis and design of extreme and high failure consequence, respectively. For facilities with a low failure consequence, the controlling ground motion can be the lower of the $50^{\text {th }}$-percentile (median) MCE, or the 1:2,500 AEP ground motions.

When the MCE ground motions are lower than the probabilistic values at the design AEP, then the controlling earthquake ground motions can be the MCE. Otherwise, the probabilistic ground motions should be used for earthquake stability analysis and design of critical facilities for closure. This approach is favoured because MCE represents the 'largest conceivable earthquake possible to occur along a fault or within a seismogenic setting' while larger earthquake ground motions can be expected to be extremely rare. Consequently, lower AEP values (e.g. 1:10,000) do not apply.

As argued in this paper, an arbitrary adoption of low to very low AEPs (i.e. long return earthquakes periods) to provide conservatism for the design of critical facilities is unnecessary when the MCE ground motion controls the design, particularly in moderate to high seismic hazard regions. The earthquake ground motion suggested for stability analysis and design of critical facilities in moderate to high seismic hazard regions should be evaluated from both PSHA and DSHA to compare earthquake ground motions estimated for discrete AEPs with the median or $84^{\text {th }}$-percentile ground motions for MCE at the site.

When DSHA is not possible because of the lack of identifiable fault sources in very low to low seismic hazard regions, then engineering judgment should be used to select the most appropriate probabilistic earthquake ground motion associated with a low AEP based on the assessed failure consequence.

In moderate and high seismic hazard regions, earthquake ground motion near-field effects developed near the crustal fault earthquake sources can generate high MCE ground motions for a low AEP (i.e. for long to very long earthquake return periods). If large magnitudes (e.g. $\mathbf{M} \geq 6.0$ ) are from a fault rupture and the source-to-site distance is relatively close (e.g. less than $10 \mathrm{~km}$ ), then the impact of near-field effects in the ground motion selection criteria may require engineering judgment based on the owner's risk-based decisions. 
Although earthquake performance targets recommended in this paper are not necessarily the same as used in seismic design for closure for different components of mine facilities (e.g. heap leach pads, waste-rock dumps, ponds, and other complex engineered structures), the procedure proposed here can be similarly applied based on their failure consequence.

\section{$7 \quad$ Glossary}

\section{Annual exceedance probability (AEP) \\ Consequence of failure}

\author{
Crustal fault
}

Earthquake

Earthquake ground motions

\section{Holocene}

Maximum credible earthquake (MCE)
Estimated probability for an earthquake ground motion threshold to be equalled or exceeded in a given exposure time (e.g. 1 in 475, or 1:475, associated with a $10 \%$ probability of exceedance in 50 years).

The effects resulting from a hypothetical critical facility failure or collapse. For instance, in the case of water reservoir or tailings storage facility dams, a potential failure is an uncontrolled release of water and/or the tailings.

A crustal fault is a mappable geologic structure known to have produced earthquakes in the recent geological past, including fault with evidence for surface rupture in the Holocene (i.e. in the last 11,700 years), large faults with surface displacement in the Late Pleistocene (i.e. between 11,700 and 130,000 years ago), and major faults which have moved repeatedly in Quaternary time (i.e. approx. 2.6 million years ago).

A sudden motion vibration in the earth caused by an abrupt release of energy due to a fault rupture or a subduction mechanism. Earthquakes produce a range of seismic waves (e.g. S-wave, P-wave, Love and Rayleigh) that travel through the earth and along its surface.

Movement of the earth's surface or ground shaking (i.e. ground acceleration, velocity or displacement) produced by seismic waves during an earthquake. This concept is used to describe the probabilistic or deterministic seismic hazard acceleration response spectra and earthquake acceleration time histories. The acceleration is the more commonly parameter used for ground motions (e.g. peak ground acceleration (PGA), or spectral accelerations). The term 'earthquake design ground motion' refers to the parameters selected for the seismic stability analysis and seismic validation of a structure or facility.

Geological Epoch of the Quaternary Period for the past 11,700 years. The Holocene includes most of the period since the end of the most recent ice age in most higher latitude regions. For engineering purposes, if a fault has ruptures to the ground surface in the Holocene, then the fault is commonly considered seismically 'active'.

The MCE is used only in deterministic seismic hazard analysis (DSHA) to represent the 'largest reasonably conceivable earthquake that is considered possible along a recognised fault, or within a geographically defined tectonic province, under the presently known or presumed tectonic framework' (ICOLD 2010, 2016). By definition, the MCE does not explicitly consider the earthquake return period. This MCE definition should not be confused with the Maximum Considered Earthquake defined in the USA standard American Society of Civil Engineers (ASCE 2015) 7 and the International Building Code (IBC 2015) seismic provisions with an AEP of $1: 2,475$. 


\section{Earthquake magnitude}

\section{Moment magnitude}

Near-field effects

\section{Operating basis earthquake (OBE)}

Pleistocene

\section{Recurrence interval}

Return period

Safety evaluation earthquake (SEE)

\section{Seismic hazard}

Seismic risk
Quantification of an earthquake's relative size. Earthquake magnitude is based on measurement of the instrumentally recorded amplitude (e.g. in a seismograph). Many magnitude scales have been defined, but the most commonly used are the local or Richter magnitude $\left(\mathrm{M}_{\mathrm{L}}\right)$, the surface-wave magnitude $(M s)$, the body-wave magnitude $\left(\mathrm{M}_{\mathrm{b}}\right)$, and moment magnitude ( $\mathbf{M}$ or $\left.\mathbf{M w}\right)$.

Measure of the energy released at the earthquake source (i.e. at the earthquake hypocentre) its area (i.e. crustal faults or subduction source zones), and the average slip rate on the fault source.

Impact typically produced by ruptured faults at a close site-to-source distance, and moderate-to-large magnitude earthquakes (e.g. $\mathbf{M} \geq 6.0$ ). Although the site-tosource distance defined for near-field earthquakes not well defined, the range of interest can vary from 5 to $50 \mathrm{~km}$. In the near-field zone, earthquake ground motions may be associated with one or multiple short-duration large pulses, distinctive directivity, residual displacements and high-frequency content.

Earthquake performance level for which a critical facility (components and equipment also needed for its safety function and operation) is designed to remain operational, with any damage being minor and readily repairable following the event. For the OBE level the ground motion is expected to cause no structural damage (cracks, deformations, leakage etc.), or limited damage and deformations repairable without significantly disrupting operations.

Geologic Epoch of the Quaternary Period defined between about 11,700 years before present and about 2,600,000 years ago. Faults of Pleistocene age may show some level of seismogenic capacity though their average slip rates and earthquake recurrence intervals are usually lower than faults that have been active in the Holocene Epoch.

Estimated average time between earthquakes within subduction source zones or faults in a specified seismotectonic region or in a specified fault zone.

The return period is the average elapsed time between occurrences of earthquake ground motions that exceeding a specified ground motion threshold (e.g. spectral acceleration) for a defined exposure period. Return period is the inverse of the annual exceedance probability (i.e. 1/AEP).

An earthquake performance level that would result in the most severe ground motion which a critical facility must be analysed and designed to avoid partial or total collapse (e.g. in the case of dams, no uncontrolled release of the reservoir). During the SEE, post-elastic deformations may occur in some facility's sections.

Inherent natural occurrence of earthquakes within a geographically defined geologic province under a presently known or a presumed tectonic framework. Seismic hazard may also include surface faulting rupture, ground shaking, landslide, liquefaction, tectonic deformation, tsunamis, seiches, and other shaking-related phenomena.

Combined impact of the probability of occurrence (hazard) and the associated consequence (e.g. structural vulnerability) overall possible scenarios. Seismic risk is the product of the seismic hazard and the facility's structural vulnerability. Earthquake risk is the probable damage, including the number of people expected to be hurt or killed if a likely earthquake occurs and the economic losses expected. Important: earthquake hazard and earthquake risk are commonly incorrectly used as interchangeable. 


\section{Spectral acceleration (Sa)}

Response acceleration of a facility modelled as a simplified single degree of freedom (SDOF) oscillator having the same structural natural period of vibration of the facility. In turn, the peak ground acceleration (PGA) is the maximum acceleration experienced by a soil-particle during an instrumentally recorded earthquake. Both parameters (PGA and Sa) are typically expressed as a fraction of the acceleration of gravity $\left(\mathrm{g}=9.805 \mathrm{~m} / \mathrm{s}^{2}\right)$.

Dam or embankment and complementary structures analysed, designed and built to retain tailings or other waste materials from mining or industrial operations.

\section{Tailings storage facility (TSF)}

\section{References}

American Society of Civil Engineers 2015, Minimum Design Loads for Buildings and Other Structures, Reston.

Australian National Committee on Large Dams 2017, Australian Guidelines for Design of Dams and Appurtenant Structures for Earthquake, Hobart.

Canadian Dam Association 2014, Bulletin: Application of Dam Safety Guidelines to Mining Dam, Toronto.

Cornell, CA 1968, 'Engineering seismic risk analysis', Bulletin of Seismological Society of America, vol. 58, no. 5, pp. $1583-1606$.

Garbarino, E, Orveillon, G, Saveyn, HGM, Barthe, P \& Eder, P 2018, Best Available Techniques Reference Document for the Management of Waste from Extractive Industries, European Commission, Seville.

Grigull, S, Sutinen, R \& Kosonen, E 2015, 'Faults active during the Quaternary period', in A Korja \& E Kosonen (eds), Seismotectonic Framework \& Seismic Source Area Models in Fennoscandia, Northern Europe, Institute of Seismology and University of Helsinki, Report S-63, pp. 49-62.

International Council on Mining and Metals 2008, Planning for Integrated Mine Closure: Toolkit, London.

International Commission on Large Dams 2010, Bulletin 72: Selecting seismic parameters for large dams: Guidelines, Committee on Seismic Aspects of Dam Design, International Commission on Large Dams, Paris.

International Commission on Large Dams 2013, Bulletin 153: Sustainable Design and Post-closure Performance of Tailings Dams, Paris. International Commission on Large Dams 2016, Bulletin 148: Selecting Seismic Parameters for Large Dams. Guidelines, Committee on Seismic Aspects of Dam Design, International Commission on Large Dams, Paris.

International Code Council 2015, International Building Code, Washington.

Johnson, AC, Coppersmith, KJ, Kaner, LR \& Cornell CA 1994, The Earthquakes of Stable Continental Regions, Electric Power Research Institute publication TR-102261-V1, Electric Power Research Institute, Palo Alto.

Korja, A 2015, 'Discussion', in A Korja \& E Kosonen (eds), Seismotectonic Framework \& Seismic Source Area Models in Fennoscandia, Northern Europe, Institute of Seismology and University of Helsinki, Report S-63, pp. 212-215.

Landgraf, A, Kubler, S, Hintersberger, E and Stein, S (eds) 2017, 'Seismicity, fault rupture and earthquake hazards in slowly deforming regions', Geological Society of London Special Publication, https://doi.org/10.1144/SP432

New Zealand Society on Large Dams 2016, New Zealand Society of Large Dams. Dam Safety Guidelines.

Olesen O, Blikra LH, Braathen A, Dehls JF, Olsen L, Rise L, Roberts D, Riis F, Faleide JI \& Anda E 2004, 'Neotectonic deformation in Norway \& its implications: A review', Norwegian Journal of Geology, vol. 84, pp. 3-34.

Quigley, MC, Cupper, ML \& Sandiford, M 2006, 'Quaternary faults of south-central Australia: palaeoseismicity, slip rates \& origin', Australian Journal of Earth Sciences, vol. 53, pp. 285-301.

Quigley, M, Clark, D \& Sandiford, M 2010, 'Tectonic geomorphology of Australia', in P Bishop, B Pillans (eds), Australian Landscapes, Geological Society of London Special Publication 346, pp. 243-265.

Schafer H, Slingerland N, Macciotta R, Beier N 2018, 'Overview of current state of practice for closure of tailings dams', Proceedings of the 6th International Oil Sands Tailings Conference, University of Alberta, Edmonton.

Sutinen, R, Kosonen, E \& Lund, B 2015, 'Glaciation cycles in the Quaternary Period', in A Korja \& E Kosonen (eds), Seismotectonic Framework \& Seismic Source Area Models in Fennoscandia, Northern Europe, Institute of Seismology and University of Helsinki, Report S-63, pp. 89-101.

Wieland, M 2012, 'Seismic Design \& Performance criteria for large storage dams', Proceedings of the 15th World Conference on Earthquake Engineering, Committee on Seismic Aspects of Dam Design and International Commission on Large Dams.

Wieland, M 2016, 'Safety aspects of sustainable storage dams and earthquake safety of existing dams', Engineering, vol. 2, iss. 3, pp. 325-331, http://dx.doi.org/10.1016/J.ENG.2016.03.011

Wu, P, Johnston, P \& Kambeck, K 1999, 'Postglacial Rebound and Fault Instability in Fennoscandia', Geophysical Journal International, vol. 139 , pp. $657-670$. 